\title{
Antibiotic susceptibilities, serotypes and auxotypes of Neisseria gonorrhoeae isolated in New Zealand
}

\author{
M SY Brett, H G D Davies, J R Blockley, H M Heffernan
}

\begin{abstract}
Objective-The aim of the study was to determine the distribution of auxotypes and serotypes and the prevalence of antibiotic resistance among New Zealand isolates of Neisseria gonorrhoeae.

Materials and methods-A total of 486 gonococci isolated in 1988 were auxotyped, serotyped, and tested for susceptibilities to ten antibiotics.

Results-The gonococci were susceptible to all the antibiotics tested except penicillin and tetracycline. Eleven $(2 \cdot 2 \%)$ produced beta-lactamase, one $(0 \cdot 2 \%)$ showed chromosomal penicillin resistance, and 18 (3.7\%) were resistant to a low-level of tetracycline. Most of the gonococci belonged to six auxotypes. The three predominant auxotypes were argininerequiring ( $\mathrm{Arg}^{-}$), non-requiring (NR), and arginine, hypoxanthine, uracilrequiring $\left(\mathrm{AHU}^{-}\right)$. The majority of the isolates belonged to serogroup IB and to six serovars. The most prevalent serovars were IB-3 and IB-1. There was an association between penicillin susceptibility and auxotype or serovar among non-penicillinase producing $\boldsymbol{N}$. gonorrhoeae (PPNG) isolates.

Conclusions-Antibiotic resistance, including penicillin resistance, remains uncommon among gonococci in New Zealand. Baselines have been established for future epidemiological studies using both auxotyping and serotyping.
\end{abstract}

\section{Introduction}

The worldwide distribution of Neisseria gonorrhoeae and the emergence of new plasmidmediated $^{1}$ and chromosomal resistances ${ }^{2}$ emphasise the importance of epidemiological study of $N$. gonorrhoeae and surveillance of its susceptibility to antibiotics commonly used for therapy. Serotyping ${ }^{3}$ and auxotyping ${ }^{4}$ are powerful tools that can be used in the epidemiological study of gonococcal infections. To achieve the full potential from auxotype/serovar analysis, it is necessary to have data on the auxotypes and serovars of strains within geographical areas. Previous national surveys in $1976^{5}$ and 1980 (Green, unpublished observations) showed low rates of antibiotic resistance among gonococci in New Zealand. In this study, we report on the distribution of auxotypes and serotypes, and the prevalence of antibiotic resistance among New Zealand isolates of $N$. gonorrhoeae in 1988.

\section{Materials and methods \\ Bacterial strains}

A total of $486 N$. gonorrhoeae from genital sites were tested. The isolates were referred to the New Zealand Communicable Disease Centre by 39 laboratories throughout New Zealand in 1988. Isolates were identified as $N$. gonorrhoeae as described previously. ${ }^{6}$ All isolates were cultured on GC Medium (Difco Laboratories), supplemented with $1 \%$ haemoglobin (Difco) and 1\% Isovitalex (BBL). Organisms were stored at $-70^{\circ} \mathrm{C}$ in Tryptic Soy Broth (Difco) containing 15\% (v/v) glycerol.

Antibiotic susceptibility tests

The antimicrobial susceptibilities were determined by an agar dilution method $^{7}$ using Isosensitest agar with $8 \%$ lysed horse blood and an inoculum of $10^{4} \mathrm{cfu}$. The plates were read after $18-20 \mathrm{~h}$ incubation at $35^{\circ} \mathrm{C}$ with $5 \%$ $\mathrm{CO}_{2}$. The antimicrobials tested were Augmentin, cefotaxime, cefoxitin, ceftriaxone, cefuroxime, ciprofloxacin, co-trimoxazole, penicillin, spectinomycin, and tetracycline. Beta-lactamase production was tested by a chromogenic cephalosporin method. ${ }^{8}$

\section{Plasmid profiles}

Plasmid profiles were determined for the penicillinase-producing $N$. gonorrhoeae (PPNG) isolates. Plasmid DNA was extracted by a rapid method, ${ }^{9}$ electrophoresed on $0.7 \%$ agarose and visualised by ethidium bromide staining.

\section{Serotyping}

The isolates were serotyped by a coagglutination method using a panel of six Protein IAspecific and six Protein IB-specific monoclonal antibodies. ${ }^{3}$ Serovars were designated by the nomenclature of Knapp et $a l^{3}$ In accordance with others, ${ }^{10}$ 11 serovars which belong to IA-1 and IA-2 or to IB-5 and IB-7 were considered as single serovars.

\section{Auxotyping}

All isolates were tested for their nutritional requirement for-arginine, hypoxanthine, uracil, proline, and methionine by modification of a previously described method ${ }^{12}$ using Gonococcal Genetic Medium (GGM) ${ }^{13}$ as the defined minimal medium.

\section{Statistical analysis}

Differences in penicillin susceptibility of the predominant serovars and auxotypes of nonPPNG isolates were determined using the chi square test. 
Table 1 Susceptibility of 486 gonococci to ten antibiotics

\begin{tabular}{|c|c|c|c|c|c|c|}
\hline \multirow[b]{3}{*}{ Antibiotic } & \multicolumn{6}{|l|}{$M I C(m g / l)$} \\
\hline & \multicolumn{3}{|c|}{ Non-PPNG $(n=475)$} & \multicolumn{3}{|c|}{ PPNG $(n=11)$} \\
\hline & Range & $M I C_{\text {so }}$ & $M I C_{90}$ & Range & $M I C_{\text {so }}$ & $M I C_{90}$ \\
\hline $\begin{array}{l}\text { Augmentin } \\
\text { Cefotaxime } \\
\text { Cefoxitin } \\
\text { Ceftriaxone } \\
\text { Cefuroxime } \\
\text { Ciprofloxacin } \\
\text { Co-trimoxazole† } \\
\text { Penicillin } \\
\text { Spectinomycin } \\
\text { Tetracycline }\end{array}$ & $\begin{array}{l}0.004-1 \\
0.004-0.06 \\
0.06-2 \\
0.004-0.06 \\
0.004-1 \\
0.004-0.008 \\
0.06-1 \cdot 0 \\
0.004-1.0 \\
2-32 \\
0.06-2\end{array}$ & $\begin{array}{l}0.12 \\
0.004 \\
0.12 \\
0.004 \\
0.016 \\
0.004 \\
0.12 \\
0.03 \\
8 \\
0.25\end{array}$ & $\begin{array}{l}0 \cdot 25 \\
0 \cdot 008 \\
0 \cdot 25 \\
0.004 \\
0.03 \\
0.004 \\
0 \cdot 5 \\
0 \cdot 12 \\
8 \\
1\end{array}$ & $\begin{array}{l}0.5-2 \\
0 \cdot 004-0.008 \\
0 \cdot 25-1 \\
0.004 \\
0.016-0.06 \\
0 \cdot 004-0.008 \\
0 \cdot 12-1 \cdot 0 \\
2 \cdot 0-64 \\
4-32 \\
1-2\end{array}$ & $\begin{array}{l}1 \\
0.004 \\
0.5 \\
0.004 \\
0.06 \\
0.004 \\
0.5 \\
16 \\
8 \\
2\end{array}$ & $\begin{array}{l}2 \\
0.008 \\
1 \\
0.004 \\
0.06 \\
0.008 \\
1.0 \\
32 \\
8 \\
2\end{array}$ \\
\hline
\end{tabular}

^ Expressed as concentration of amoxycillin

+ Expressed as concentration of trimethoprim in trimethoprim:sulphamethoxazole of 1:19

MIC $_{50}$ : MICs required to inhibit $50 \%$ of isolates

MIC $_{90}$ : MICs required to inhibit $90 \%$ of isolates

\section{Results}

Antibiotic susceptibility

The gonococcal isolates were susceptible to all the antibiotics tested except penicillin and tetracycline. Eleven $(2 \cdot 2 \%)$ produced betalactamase, one $(0.2 \%)$ showed chromosomal penicillin resistance, and $18(3 \cdot 7 \%)$ were resistant to a low-level of tetracycline. The antibiotic susceptibilities of the 475 nonPPNG and 11 PPNG isolates are shown in table 1.

Seven $(64 \%)$ of the PPNG isolates were tetracycline-resistant (MIC $>=2 \mathrm{mg} / \mathrm{l})$. No plasmid mediated high-level tetracycline resistance (MIC $\geq 16 \mathrm{mg} / \mathrm{l}$ ) was seen. Plasmid analyses showed that eight isolates carried the Asian type beta-lactamase plasmid ( $4.5 \mathrm{Md})$, two isolates the Rio/Toronto type plasmid ( $3.0 \mathrm{Md})$, and one isolate the African type plasmid (3.2 Md). Transfer plasmids (24.5 Md) were carried by all the PPNG isolates except two with the Asian type plasmid.

Among the non-PPNG isolates, 11 were resistant to a low-level of tetracycline and one showed chromosomal penicillin resistance (MIC $\geq 1 \mathrm{mg} / \mathrm{l}$ ). The distribution of the penicillin MICs of the non-PPNG isolates (fig) was bimodal. Of the non-PPNG isolates, $50.9 \%$ were penicillin-sensitive (MIC $\leq 0.03 \mathrm{mg} / \mathrm{l}$ ) and $48.9 \%$ were penicillin less sensitive (MIC $0.06-0.5 \mathrm{mg} / \mathrm{l})$.

\section{Serotyping}

Serotyping of the 11 PPNG isolates showed that one belonged to serogroup IA and ten to

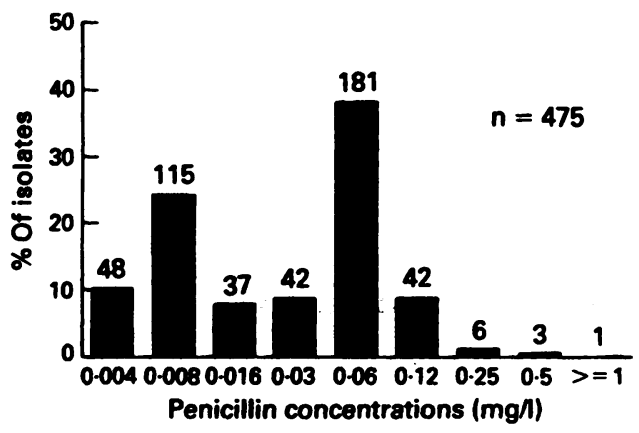

Fig Distribution of penicillin MICs of 475 non-PPNG isolates. serogroup IB. Six serovars were found among the PPNG isolates; four isolates were IB-1 and three isolates were IB-3.

Sixteen serovars, four IA and 12 IB specific serovars, were represented among the 475 non-PPNG isolates serotyped. However, most $(91.8 \%)$ of the isolates belonged to six predominant serovars (table 2). A total of 447 $(94 \cdot 1 \%)$ isolates were IB serovars. The most prevalent serovars were IB-3 and IB-1 which accounted for $71.2 \%$ of the isolates.

The distribution of the six predominant serovars among the non-PPNG isolates that were either penicillin-sensitive (MIC $\leq 0.03$ $\mathrm{mg} / \mathrm{l}$ ) or penicillin less sensitive (MIC $0.06-0.5 \mathrm{mg} / 1)$ is shown in table 2 . There was a significant $(p<0.001)$ association between serovar and penicillin susceptibility. There were more serovar IB-14, IB-5/7 and IB-3 isolates among the penicillin less sensitive group and more serovar IB-1 isolates among the penicillin-sensitive group.

\section{Auxotyping}

Six auxotypes were represented among the 11 PPNG isolates. Four PPNG isolates were $\mathrm{Pro}^{-}$ (proline-requiring) and two were NR (nonrequiring). Of the 475 non-PPNG isolates, $454(95 \cdot 6 \%)$ belonged to six predominant auxotypes (table 3). A total of 14 auxotypes were found. The most prevalent auxotypes were $\mathrm{Arg}^{-}$(arginine-requiring), $\mathrm{AHU}^{-}$(arginine, hypoxanthine, uracil-requiring) and NR. There were 23 isolates that required arginine, hypoxanthine, uracil and methionine. Five of these isolates were inconsistent in their requirement for methionine.

Table 3 shows the distribution of the six predominant auxotypes among non-PPNG isolates that were either penicillin-sensitive (MIC $\leq 0.03 \mathrm{mg} / \mathrm{l}$ ) or penicillin less sensitive (MIC $0.06-0.5 \mathrm{mg} / \mathrm{l})$. There was a significant correlation $(p<0.001)$ between penicillin susceptibility and auxotype. There were more NR and $\mathrm{Arg}^{-}$isolates among the penicillin less sensitive group; and more $\mathrm{AHU}^{-}, \mathrm{AHUM}^{-}$, and ProArg ${ }^{-}$isolates among the penicillinsensitive group.

\section{Auxotype/Serovar classes}

There were ten auxotype/serovar (A/S) classes among the $11 \mathrm{PPNG}$ isolates and $60 \mathrm{~A} / \mathrm{S}$ 
Table 2 Predominant serovars among 475 non-PPNG isolates

\begin{tabular}{|c|c|c|c|}
\hline \multirow[b]{2}{*}{ Serovar } & \multirow[b]{2}{*}{$\begin{array}{l}\text { Number (\%) of } \\
\text { total isolates }\end{array}$} & \multicolumn{2}{|c|}{ Number (\%) of total isolates that were: } \\
\hline & & $\begin{array}{l}\text { Penicillin-* } \\
\text { sensitive }\end{array}$ & $\begin{array}{l}\text { Penicillin lesst } \\
\text { sensitive }\end{array}$ \\
\hline $\begin{array}{l}\text { IB-3 } \\
\text { IB-1 } \\
\text { IB-14 } \\
\text { IB-2 } \\
\text { IA-1/2 } \\
\text { IB-5/7 } \\
\text { Totals }\end{array}$ & $\begin{array}{c}216(45 \cdot 5) \\
122(25 \cdot 7) \\
32(6 \cdot 7) \\
26(5 \cdot 5) \\
22(4 \cdot 6) \\
18(3 \cdot 8) \\
436(91 \cdot 8)\end{array}$ & $\begin{array}{c}94(19 \cdot 8) \\
93(19 \cdot 6) \\
5(1 \cdot 0) \\
17(3 \cdot 6) \\
16(3 \cdot 4) \\
2(0 \cdot 4) \\
227(47 \cdot 8)\end{array}$ & $\begin{aligned} & 121(25 \cdot 5) \\
& 29(6 \cdot 1) \\
& 27(5 \cdot 7) \\
& 9(1 \cdot 9) \\
& 6(1 \cdot 2) \\
& 16(3 \cdot 4) \\
& 208(43 \cdot 8)\end{aligned}$ \\
\hline
\end{tabular}

$\star$ Penicillin MIC $\leq 0.03 \mathrm{mg} / \mathrm{l}$

† Penicillin MIC $=0.06-0.5 \mathrm{mg} / \mathrm{l}$

Table 3 Predominant auxotypes among 475 non-PPNG isolates

\begin{tabular}{llll}
\hline & \multicolumn{2}{l}{ Number (\%) of total isolates that were: } \\
\cline { 3 - 4 } Auxotype & $\begin{array}{l}\text { Number (\%) of } \\
\text { total isolates }\end{array}$ & $\begin{array}{l}\text { Penicillin-* } \\
\text { sensitive }\end{array}$ & $\begin{array}{l}\text { Penicillin lesst } \\
\text { sensitive }\end{array}$ \\
\hline Arg & $178(37 \cdot 5)$ & $42(8 \cdot 9)$ & $136(28 \cdot 6)$ \\
AHU & $100(21 \cdot 1)$ & $97(20 \cdot 5)$ & $3(0 \cdot 6)$ \\
NR & $87(18 \cdot 3)$ & $29(6 \cdot 1)$ & $58(12 \cdot 2)$ \\
ProArg & $39(8 \cdot 2)$ & $28(5 \cdot 9)$ & $10(2 \cdot 1)$ \\
Pro & $27(5 \cdot 7)$ & $10(2 \cdot 1)$ & $17(3 \cdot 6)$ \\
AHUM & $23(4 \cdot 8)$ & $23(4 \cdot 8)$ & $0(0)$ \\
Totals & $454(95 \cdot 6)$ & $229(48 \cdot 3)$ & $224(47 \cdot 1)$ \\
\hline
\end{tabular}

$\star$ Penicillin MIC $\leq 0.03 \mathrm{mg} / \mathrm{l}$

$\dagger$ Penicillin MIC $=0.06-0.5 \mathrm{mg} /$

$\mathrm{Arg}=$ arginine-requiring; $\mathrm{AHU}=$ arginine, hypoxanthine, uracil-requiring; $\mathrm{NR}=$ non-requiring; ProArg = proline, arginine-requiring; Pro = proline-requiring; AHUM = arginine, hypoxanthine, uracil, methionine-requiring.

classes among the 475 non-PPNG isolates. The distribution of the non-PPNG isolates among the six predominant auxotypes and serovars is shown in table 4 . The main A/S class among the non-PPNG isolates was $\mathrm{Arg}^{-} / \mathrm{IB}-3$ which accounted for $99(20.3 \%)$ of the isolates tested.

The single isolate with chromosomal penicillin resistance was in the A/S class ProArg ${ }^{-} /$ IB-3. Eighty-seven per cent of the $\mathrm{Arg}^{-} / \mathrm{IB}-14$, $85 \%$ of $\mathrm{NR} / \mathrm{IB}-5 / 7$, and $84 \%$ of $\mathrm{Arg}^{-} / \mathrm{IB}-1$ isolates were penicillin less sensitive.

\section{Discussion}

Comparison of the antibiotic susceptibilities of gonococci in the present study with the earlier national surveys in $1976^{5}$ and 1980 (Green, unpublished observations) shows that there have been no appreciable changes in antibiotic susceptibilities except for penicillin. In the 1980 study, $4.7 \%$ of 318 isolates had penicillin MICs of $1-4 \mathrm{mg} / 1$ compared with $0.2 \%$ in the present study. However, it is difficult to assess the significance of the apparent decrease as a different sensitivity testing medium was used in the earlier studies. In the 1976 and 1980 studies, the medium used was Proteose No 3 agar supplemented with $1 \%$ haemoglobin and $1 \%$ Isovitalex. In a comparative study ${ }^{14}$ of the effect of media on penicillin MICs, it was shown that Isosensitest agar with $8 \%$ lysed horse blood tended to give lower readings than other media tested.

Our results show that gonococci isolated in New Zealand are very susceptible to most antibiotics; just penicillin resistance and lowlevel tetracycline resistance were identified and only among a small percentage of the isolates surveyed. There were no PPNG isolates in the 1976 survey although the first PPNG isolated in New Zealand was confirmed shortly after the survey ended. There were $12(3.2 \%)$ PPNG isolates in the 1980 survey and 11 $(2 \cdot 2 \%)$ PPNG isolates in the present study. This contrasts with reported PPNG isolation rates of $40-50 \%$ in parts of Asia $^{1516}$ and $40-80 \%$ in parts of Africa. ${ }^{17} 18$

Similarly, our rate of chromosomal penicillin resistance at $0.2 \%$ is considerably lower than Britain, ${ }^{19}$ the United States, ${ }^{20}$ and Australia. ${ }^{21}$ It has been reported that in the Far East there is a high prevalence of chromosomal penicillin resistance. In one study, $53 \%$ of non-PPNG isolates isolated in Bangkok have penicillin MICs $\geq 1 \mathrm{mg} / 1$. $^{16}$

It was notable that $\mathrm{Arg}^{-}, \mathrm{AHU}^{-}$and $\mathrm{NR}$ strains predominated in New Zealand. Studies have shown that the predominant auxotypes in the Netherlands, ${ }^{22}$ Britain, ${ }^{19}$ Greece, ${ }^{23}$ Jamaica, ${ }^{24}$ Korea, $^{25}$ Chile, $^{26}$ and Argentina ${ }^{27}$ are NR and Pro ${ }^{-}$. We showed that $94 \cdot 1 \%$ of our isolates belonged to serogroup IB. Similarly, several studies ${ }^{3924}$ have shown the predominance of serogroup IB strains in many geographical areas.

Our results showed an association between auxotype or serotype and penicillin sensitivity. The correlation of $\mathrm{AHU}^{-}$strains with penicillin susceptibility has been previously shown. ${ }^{2829}$ Our study confirmed the significant association of the $\mathrm{AHU}^{-}$auxotype with penicillin sensitivity. We further showed the significant correlation of the $\mathrm{AHUM}^{-}$and ProArg ${ }^{-}$auxotypes with penicillin sensitivity. Association between serovar IB-5/7 and chromosomal penicillin resistance has been previously shown. ${ }^{9}$ Our results show that serovars IB-14, IB-5/7 and IB-3 predominated among the penicillin less sensitive strains.

It is of note that our results showed that $88 \%$ of the AHU-isolates belonged to serogroup IB.

Table 4 Distribution of 475 non-PPNGs among six predominant serovars and six predominant auxotypes

\begin{tabular}{|c|c|c|c|c|c|c|c|c|}
\hline \multirow[b]{2}{*}{ Serovar } & \multicolumn{8}{|c|}{ Auxotype } \\
\hline & Arg & $A H U$ & $N R$ & ProArg & Pro & $A H U M$ & Others & Total \\
\hline IB-3 & 99 & 36 & 58 & 3 & 12 & 4 & 4 & 216 \\
\hline IB-1 & 25 & 48 & 5 & 16 & 3 & 16 & 9 & 122 \\
\hline IB-14 & 31 & 1 & & & & & & 32 \\
\hline IB-2 & 8 & 1 & 1 & 11 & 2 & & 3 & 26 \\
\hline IA $-1 / 2$ & 2 & 12 & & 5 & & 3 & & 22 \\
\hline IB-5/7 & 3 & & 13 & & & & 2 & 18 \\
\hline Others & 10 & 2 & 10 & 4 & 10 & & 3 & 39 \\
\hline Total & 178 & 100 & 87 & 39 & 27 & 23 & 21 & 475 \\
\hline
\end{tabular}

Arg = arginine-requiring; $\mathrm{AHU}=$ arginine, hypoxanthine, uracil-requiring: $\mathrm{NR}=$ non-requiring: Pro $=$ proline-requiring; AHUM = arginine, hypoxanthine, uracil, methionine-requiring. 
With the exception of another study ${ }^{11}$ where $46 \%$ of the AHU-isolates were AHU/IB strains, other studies ${ }^{30}$ have shown that most AHU-isolates belonged to serogroup IA.

There were too few PPNG isolates to show adequately any correlation between serovars and auxotypes. However, the wide variety of auxotypes, serovars and plasmid types among 11 isolates of PPNG suggest the importation of strains from other countries rather than local circulation of a few strains.

In conclusion, we showed that antibiotic resistance, including penicillin resistance, remains uncommon among gonococci in New Zealand. We have also established baselines for future epidemiological studies using auxotype/ serovar typing.

This paper is published with the authority of the DirectorGeneral of Health, New Zealand.

1 Knapp JS, Zenilman JM, Biddle JW, et al. Frequency and distribution in the United States of strains of Neisseric gonorrhoeae with plasmid-mediated, high-level resistance to tetracycline. $\mathcal{F}$ Infect Dis 1987;155:819-22.

2 Easmon CSF, Ison CA. Neisseria gonorrhoeae: a versatile pathogen. $\tilde{f}$ Clin Pathol 1987;40:1088-97.

3 Knapp JS, Tam MR, Nowinski RC, Holmes KK, Sandström EG. Serological classification of Neisseria gonorrhoeae with use of monoclonal antibodies to gonococcal outer membrane protein I. $\mathcal{F}$ Infect Dis 1984;150:44-8.

4 Catlin BW. Nutritional profiles of Neisseria gonorrhoeae, Neisseria meningitidis and Neisseria lactamica in chemically defined media and the use of growth requirements for defined media and the use of growth requirements
gonococcal typing. $\mathcal{f}$ Infect Dis 1973;128:178-94.

5 Green MJ. In-vitro antimicrobial susceptibility of Neisseria gonorrhoeae in New Zealand. Brit $\mathcal{J}$ Venereal Dis 1978;54:316-21.

6 Brett MSY. Conjugal transfer of gonococcal beta-lactamase and conjugative plasmids to Neisseria meningitidis. $\mathcal{f}$ Antimicrob Chemother 1989;24:875-9.

7 Australian gonococcal surveillance programme. Penicillin sensitivity of gonococci in Australia: development of Australian gonococcal surveillance programme. Brit Venereal Dis 1984;60:226-30.

8 O'Callaghan CH, Morris A, Kirby SM, Shingler AH. Novel method for detection of beta-lactamases by using a chromogenic cephalosporin substrate. Antimicrob Agents Chemother 1972;1:283-8.

9 Kado CI, Liu ST. Rapid procedure for detection and isolation of large and small plasmids. $\not$ Bacteriol 1981;145:1365-73.

10 Woodford N, Bindayna KM, Easmon CS, Ison CA. Associations between serotype and susceptibility to antibiotics of Neisseria gonorrhoeae. Genitourin Med 1989;65:86-91

11 Knapp JS, Holmes KK, Bonin P, Hook EW III. Epidemiology of gonorrhoea: distribution and temporal changes in auxotype/serovar classes of Neisseria gonorrhoeae. Sex Transm Dis 1987;14:26-32.
12 Knapp JS, Holmes KK. Disseminated gonococcal infections caused by Neisseria gonorrhoeae with unique nutritional requirements. $\mathcal{f}$ Infect Dis 1975;132:204-8.

13 La Scolea LJ, Young FE. Development of a defined minimal medium for the growth of Neisseria gonorrhoeae. Appl Microbiol 1974;28:70-6.

14 Australian gonococcal surveillance programme. Use of quality assurance scheme in a long-term multicentric study of antibiotic susceptibility of Neisseria gonorrhoeae. Genitourin Med 1990;66:8-13

15 Piziak MV, Woodbury C, Berliner D, et al. Resistance trend of Neisseria gonorrhoeae in the Republic of Korea. Antimicrob Agents Chemother 1984;25:7-9.

16 Brown S, Biddle J, Warnnissorn T, Panikabutra K, Traisupa A. Antimicrobial resistance of Neisseria gonorrhoeae in Bangkok: is single drug treatment passe. Lancet 1982;ii:1366-8.

17 Osoba AO, Johnston NA, Ogunbanjo BO, Ochei J. Plasmid profile of Neisseria gonorrhoeae in Nigeria and efficacy of spectinomycin in treating gonorrhoea. Genitourin Med 1987;63:1-5

18 Lind I, Arborio M, Bentzon MW, et al. The epidemiology of Neisseria gonorrhoeae isolates in Dakar, Senega 1982-1986: antimicrobial resistance, auxotypes and plasmid profiles. Genitourin Med 1991;67:107-13.

19 Ison CA, Gedney J, Easmon CSF. Chromosomal resistance of gonococci to antibiotics. Genitourin $\mathrm{Med}$ 1987;63:239-43

20 Schwarcz SK, Zenilman JM, Schnell D, et al. Nationa surveillance of antimicrobial resistance in Neisseria gonorrhoeae. $\mathscr{F} A M A$ 1990;264:1413-7.

21 Australian gonococcal surveillance programme. Penicillin sensitivity of gonococci isolated in Australia 1981-1986. Genitourin Med 1988;64:147-51.

22 van Klingeren B, Ansink-Schipper MC, Doornbos L, et al. Surveillance of the antibiotic susceptibility of nonpenicillinase producing Neisseria gonorrhoeae in the Netherlands from 1983 to 1986. $\mathcal{F}$ Antimicrob Chemothe 1988;21:737-44.

23 Mavrommati L, Tzelepi E, Sima A, Tzanakaki G, Kokla A Flemetakis A. Antibiotic resistance, plasmid content and auxotypes of Neisseria gonorrhoeae in Greece. $\mathcal{F}$ Antimicrob Chemother 1988;21:571-9.

24 Dillon JR, Carballo M, King SD, Braithwaite AR. Auxotypes, plasmid contents and serovars of gonococcal strains (PPNG and non-PPNG) from Jamaica. Genitourin Med 1987;63:233-8.

25 Odugbemi TO, Whittington WL, DeWitt W, et al. Epidemiological characterisation of Neisseria gonorrhoeae isolates logical characterisation of Neisseria gonorrhoeae isola
from the Far East. Brit 7 Venereal Dis 1983;59:285-8.

26 Garcia Moreno J, Dillon JR, Arroyave R, et al. Identificatio of penicillinase producing Neisseria gonorrhoeae in Chil during clinical and microbiological study of gonococca susceptibility to antimicrobial agents. Genitourin Med 1987;63:6-12.

27 Monayar HK, Ledesma A, Nobile V, Viarengo JA. Epidemiology and treatment of uncomplicated gonorrhoea caused by non-PPNG strains in Cordoba, Argentina: auxotypes, susceptibility profiles, and plasmid analyses of urethral isolates from men. Genitourin Med 1987;63:246-9.

28 Stewart IO, Hendry AT. Association between the auxogroup of Neisseria gonorrhoeae and the minimal inhibitory concentration of penicillin. Sex Transm Dis 1979;6:247-52.

29 Knapp JS, Thornsberry C, Schoolnik GA, et al. Phenotypic and epidemiologic correlates of auxotype in Neisseria gonorrhoeae. F Infect Dis 1978;138:160-5.

30 Sandström RH, Knapp JS, Reller LB, Thompson SE, Hoo EW, Holmes KK. Serogrouping of Neisseria gonorrhoeae Correlation of serogroup with disseminated gonococcal infection. Sex Transm Dis 1984;11:77-80. 